\title{
Laparoscopic management of ruptured non communicating rudimentary horn in second trimester of pregnancy
}

\author{
Akriti Jha $^{1 *}$, Richa Gupta ${ }^{1}$, Lavesh Gupta ${ }^{2}$, Deepesh Gupta ${ }^{3}$
}

${ }^{1}$ Consultant Obstetrics and gynaecology, ${ }^{2}$ Consultant Medicine and Critical Care, ${ }^{3}$ Consultant Paediatrics and Critical Care, Harish Hospital, Alwar, Rajasthan, India

Received: 16 April 2019

Revised: 15 June 2019

Accepted: 06 July 2019

\section{*Correspondence:}

Dr. Akriti Jha,

E-mail: drakritijha@gmail.com

Copyright: ( $)$ the author(s), publisher and licensee Medip Academy. This is an open-access article distributed under the terms of the Creative Commons Attribution Non-Commercial License, which permits unrestricted non-commercial use, distribution, and reproduction in any medium, provided the original work is properly cited.

\begin{abstract}
Rudimentary horn is a developmental anomaly of the uterus. Pregnancy in rudimentary horn is rare occurrence with incidence of less than 1 in 150,000. Prerupture diagnosis of rudimentary horn pregnancy with USG is technically difficult, with sensitivity of $30 \%$. It is often not diagnosed unless it terminates by rupture in the second trimester leading to catastrophic haemorrhage and hence high incidence of maternal mortality. Management of such cases is a challenge till today due to diagnostic dilemma. Expertise in ultrasonography and early resort to surgical management is life saving in such cases. Here we present a case of ruptured non-communicating rudimentary horn pregnancy at 15 weeks presenting in our emergency department as a case of pain abdomen. Laparoscopic resection of the rudimentary horn was performed for the patient.
\end{abstract}

Keywords: Noncommunicating, Pregnancy, Rudimentary, Rupture, Unicornuate

\section{INTRODUCTION}

Unicornuate uterus also more precisely called as a Hemiuterus belongs to Class U4(according to the new ESHRE-ESGE Classification) which is further subclassified as subgroup 4a-with a functional cavity which may or may not communicate and subgroup $4 \mathrm{~b}$ without a functional cavity or absent horn. ${ }^{1}$ The true prevalence of müllerian duct abnormalities is not well established because a majority of patients are asymptomatic. ${ }^{2}$ A unicornuate uterus accounts for $2.4 \%$ $13 \%$ of all mullerian anomalies. ${ }^{3}$

Rudimentary horn pregnancy is extremely rare ranging between 1 per 76,000 and 1 per 140,000 pregnancies; yet, it is associated with high rate of morbidity and mortality as a sequence of rudimentary horn rupture and massive hemoperitoneum. ${ }^{4}$ The risk of uterine rupture is nearly $90 \%$, with most ruptures occurring by the end of the second trimester. ${ }^{5}$ but silent rupture with continuation of pregnancy as secondary abdominal pregnancy was reported in some studies. Cases of pregnancy progressing to third trimester and resulting in a live birth after caesarean section have also been documented.

A very unusual case of twin pregnancy in a unicornuate uterus with one fetus in the non-communicating rudimentary horn has been reported where the outcome was successful birth of twins by caesarean section. ${ }^{6}$ Because of the life threatening complication, early prerupture diagnosis is of major importance. We report a case of second trimester rupture of noncommunicating rudimentary horn which was managed laparoscopically. 


\section{CASE REPORT}

A 28 year old G3P2L2 presented in the emergency department with pain abdomen since 2 days. She had amenorrhoea of nearly 4 months with previous two normal vaginal deliveries. She had no antenatal check-up or ultrasound till the date of admission. In our hospital, on general examination patient was very pale. Her vital signs were stable. On per abdominal examination there was generalised tenderness in lower abdomen. Bimanual examination revealed bulky uterus with cervical os closed and no active vaginal bleeding. Ultrasound showed empty uterine cavity with dead fetus corresponding to 14 weeks 5 days in right adnexal region and moderate haemoperitoneum .With ultrasound diagnosis of ectopic pregnancy and a high index of suspiscion for ruptured rudimentary horn patient was taken for laparoscopic surgery. On entering the abdomen haemoperitoneum of around three litres of blood with clots was noted Figure 1.

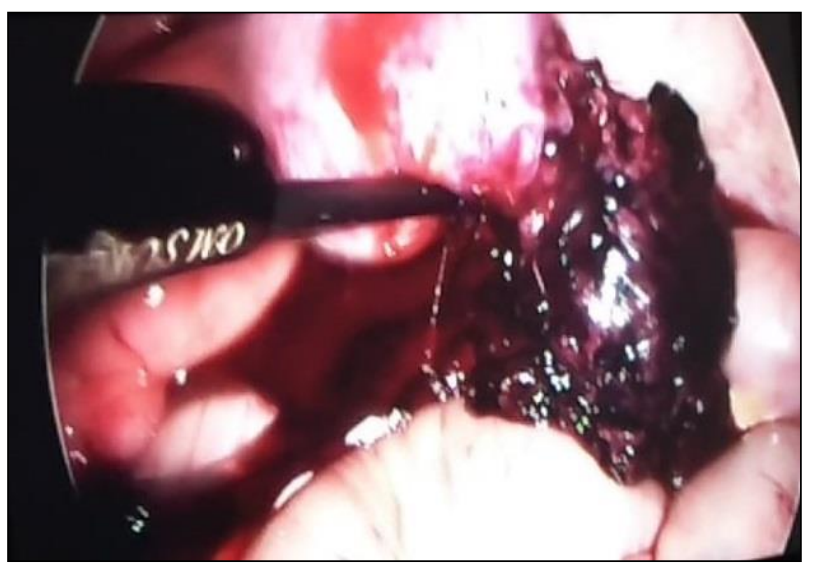

Figure 1: Gross haemoperitoneum with clots.

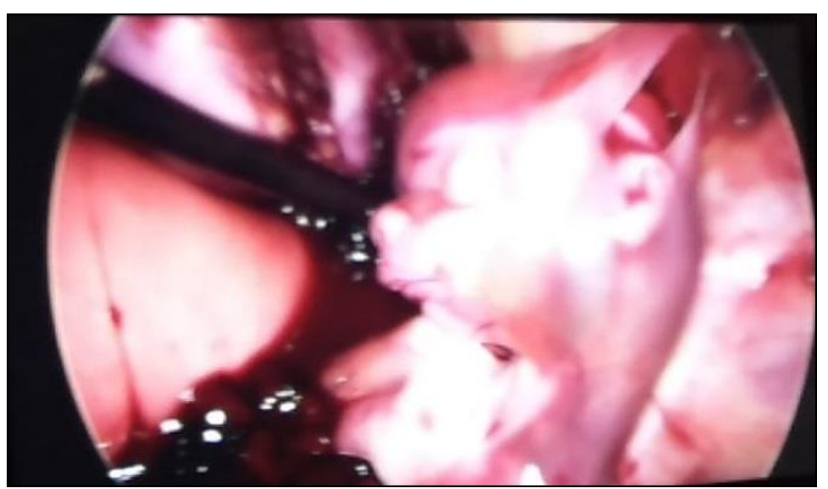

Figure 2: Dead fetus En sac lying in Abdomen.

After suctioning all the clots abdomen was inspected thoroughly. On initial pelvic evaluation, a right noncommunicating rudimentary horn connected with a fibrous band to the unicornuate uterus was observed. Both ovaries and fallopian tubes appeared normal. Before beginning surgery, right ureter was identified on the pelvic wall. The uterus lying separate in the pelvis was enlarged to 8 weeks size. There was complete rupture of right rudimentary horn of the uterus with the dead fetus lying in the intact amniotic sac covered with clots Figure 2.

\section{Dead fetus En sac lying in abdomen}

The cord and part of placenta placenta was attached to the uterine horn. The right fallopian tube and right ovary appeared normal and both were attached to the right rudimentary horn. There was no communication between the rudimentary horn and the main Unicornuate uterine cavity which was confirmed with a probe. Excision of the rudimentary horn was performed by sequential cauterising and dividing right round ligament, right fallopian tube, utero-ovarian ligament and finally the intervening band between the right rudimentary horn and the left Unicornuate uterus. Next step was excising the right fallopian tube with conservation of the right ovary. The fetus within the amniotic sac Figure 3 along with the placenta and membranes, the excised rudimentary horn Figure 4 and right fallopian tube were retrieved via endobag through port.

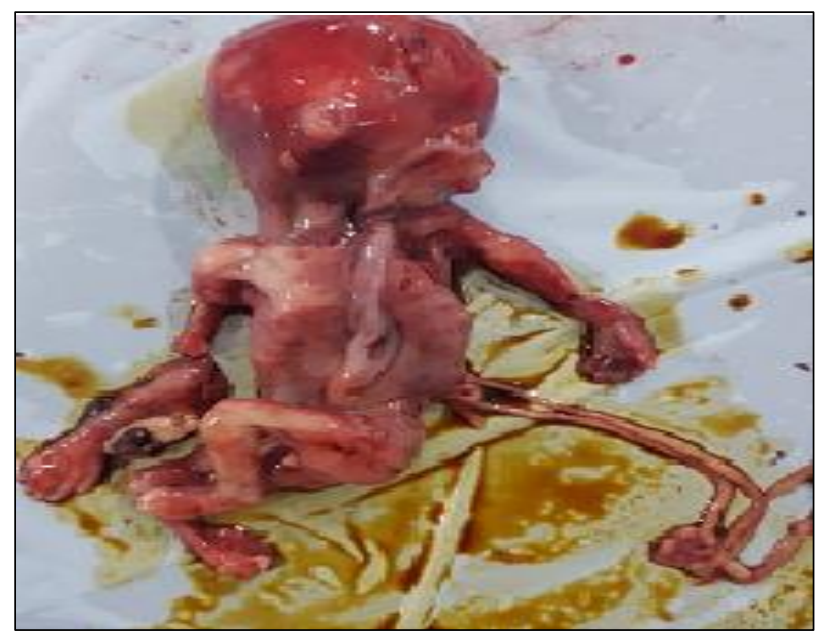

Figure 3: Dead fetus retrieved intact.

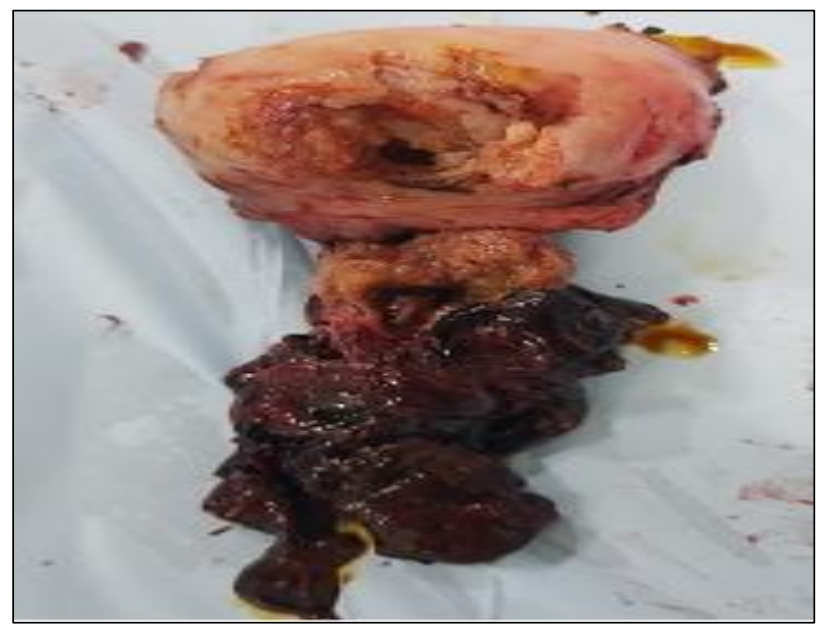

Figure 4: Ruptured horn with placenta and clots after retrieval. 
The specimen was sent for histopathological examination which was confirmed ruptured rudimentary horn of the uterus. Patient was given four units packed cells transfusion. Post-operative course of patient was satisfactory, and she was discharged on the fourth day. Patient reported after two weeks with complaints of pain abdomen which subsided with mild analgesics. A repeat abdominopelvic ultrasonography was found to be absolutely normal. No associated renal anomaly was diagnosed.

\section{DISCUSSION}

Pregnancy in a non-communicating horn of uterus is possible by intraperitoneal sperm and ovum transmigration or contralateral tubal pick up of the fertilized ovum within the peritoneal cavity. Pregnancy is a rare but serious complication of müllerian duct anomalies and is associated with significant obstetric complications and maternal mortality. Early diagnosis of rudimentary horn pregnancy is challenging, and it is not infrequent to simply overlook such an anomaly during routine gynecological evaluation.

The sensitivity of ultrasound is only $26 \%$ and sensitivity decreases as the pregnancy advances adding to the diagnostic dilemma. ${ }^{7}$ There are no definitive clinical criteria to detect this life-threatening condition in case of emergency, and diagnosis can be difficult because the enlarging horn with a thinned myometrium can obscure the adjacent anatomic structures. Magnetic resonance imaging has proven to be a very useful, noninvasive tool for the diagnosis of müllerian abnormalities; however, this expensive modality is resorted to only when rudimentary horn pregnancy is suspected either by history or by early suspicious ultrasound examination. ${ }^{8,9}$ The timing of rupture varies from 5 to 35 weeks depending on the horn musculature and its ability to hypertrophy and dilate. $70 \%-90 \%$ rupture before 20 weeks and can be catastrophic. As the uterine wall is thicker and more vascular, bleeding is more severe in rudimentary horn pregnancy rupture. ${ }^{10}$

Immediate surgery is recommended whenever rudimentary horn pregnancy is diagnosed. Surgical removal of the rudimentary horn is mandatory to avoid risk of recurrence of rupture with increased maternal morbidity. However, laparoscopic excision of unruptured rudimentary horn pregnancy has been increasingly carried out with safe and favourable outcome in many expert centres now. ${ }^{11}$

Immediate surgery is lifesaving in cases of ruptured rudimentary horn pregnancy. One important point to keep in mind is that the excision of the ipsilateral fallopian tube is recommended to prevent a further ectopic tubal gestation. ${ }^{6}$ The laparoscopic approach has been gaining popularity in recent years, which is suggested as a safe procedure.
The connection between the horn and unicornuate uterus may be fibrous or fibromuscular. If a thick fibromuscular tissue connecting the horn and uterus is present, laparoscopic removal is technically more challenging. However, in our case only a thin fibrous band was present, and therefore we did not need to close the myometrium.

\section{CONCLUSION}

Pregnancy in a non-communicating rudimentary horn is rare and carries grave consequences for the mother and the fetus. Therefore, high index of suspicion is warranted to detect this rare and very important complication of pregnancy before uterine rupture occurs. Excision of rudimentary horn is advised to prevent life threatening massive intraperitoneal haemorrhage and maternal mortality. But unfortunately, most of the cases present as emergency after the horn ruptures. For hemodynamically stable patients we recommend that laparoscopic approach is a safe procedure as it gives a much better clarity of anatomy and faster recovery of patient. However, a comprehensive preoperative workup including investigation for possible presence of urinary tract anomalies is of crucial importance to avoid associated complications.

Funding: No funding sources

Conflict of interest: None declared

Ethical approval: Not required

\section{REFERENCES}

1. Grimbizis GF, Gordts S, Di Spiezio Sardo A, Brucker S, De Angelis C, Gergolet M, et al. The ESHRE/ESGE consensus on the classification of female genital tract congenital anomalies. Human Reproduction. 2013 Jun 14;28(8):2032-44.

2. Juneja SK, Gupta S, Tandon P, Gumber N. Rupture of noncommunicating rudimentary horn of uterus. Int J Applied Basic Med Res. 2017 Apr;7(2):146.

3. Simón C, Martinez L, Pardo F, Tortajada M, Pellicer A. Müllerian defects in women with normal reproductive outcome. Fertil Steril. 1991 Dec;56(6):1192-3.

4. Tsafrir A, Rojansky N, Sela HY, Gomori JM, Nadjari M. Rudimentary horn pregnancy:Firsttrimester prerupture sonographic diagnosis and confirmation by magnetic resonance imaging. J Ultrasound Med. 2005 Feb;24(2):219-23.

5. Nahum GG. Rudimentary horn pregnancy, the 20th century worldwide experience of 588 cases. J Reprod Med. 2002 Feb;47(2):151-63.

6. Nanda S, Dahiya K, Sharma N, Aggarwal D, Singhal SR, Sangwan N. Successful Twin pregnancy in a unicornuate uterus with one fetus in the noncommunicating rudimentary horn. Arch Gynecol Obstet. 2009 Dec 1;280(6):993-5.

7. Jayasinghe Y, Rane A, Stalewski H, Grover S. The presentation and early diagnosis of the rudimentary 
uterine horn. Obstet Gynecol. 2005 Jun 1;105(6):1456-67.

8. Scarsbrook AF, Moore NR. MRI appearances of müllerian duct abnormalities. Clin Radiol. 2003 Oct 1;58(10):747-54.

9. Marten K, Vosshenrich R, Funke M, Obenauer S, Baum F, Grabbe E. MRI in the evaluation of müllerian duct anomalies. Clin Imaging. 2003 Sep 1;27(5):346-50.

10. Chowdhury S, Chowdhury T, Azim E. Pregnancy in a non-communicating rudimentary horn of uterus: A clinical case report. Bangladesh Med J. 2010;39(1):47-8.
11. Henriet E, Roman H, Zanati J, Lebreton B, Sabourin JC, Loic M. Pregnant non-communicating rudimentary uterine horn with placenta percreta. JSLS 2008;12(1):101-3.

Cite this article as: Jha A, Gupta R, Gupta L, Gupta D. Laparoscopic management of ruptured non communicating rudimentary horn in second trimester of pregnancy. Int J Reprod Contracept Obstet Gynecol 2019;8:3391-4. 